\title{
AVALIAÇÃO DA RESPOSTA INFLAMATÓRIA PERIAPICAL EM DENTES DE CÃES OBTURADOS COM DIFERENTES CIMENTOS RESINOSOS E TÉCNICAS OBTURADORAS
}

\author{
EVALUATION OF PERIAPICAL INFLAMATION RESPONSE FROM CORONAL LEAKAGE IN DOG'S TEETH \\ OBTURATED USING DIFFERENT RESIN-BASED SEALERS AND DIFFERENT OBTURATION TECHNIQUES
}

\author{
Eduardo Akisue * \\ Giulio Gavini * \\ Marco Antonio Gioso \\ Jonathan Ferreira \\ Suzana C. Orsini Machado de Sousa
}

\begin{abstract}
RESUMO
Introdução: Este estudo avalia as respostas inflamatórias periapicais resultantes da infiltração coronária em dentes de cães obturados com diferentes cimentos resinosos (AH Plus ${ }^{\oplus}$, RealSeal ${ }^{\circledR}$ e RealSeal SE ${ }^{\circledast}$ ) e técnicas obturadoras (condensação lateral e termoplástica). Método: Para tanto, pré-molares de 5 cães tiveram o tratamento endodôntico realizado e foram obturados de acordo com os grupos experimentais: GI- AHPlus/ condensação lateral, GII-AHPlus/termoplástificação, GIII-RealSeal/condensação lateral, GIV-RealSeal/ termoplástificação, GV-RealSeal SE/condensação lateral, GVI-RealSeal SE/ termoplástificação, Grupocontrole positivo e Grupo-controle negativo. As cavidades coronárias ficaram então expostas ao meio bucal por um período de 75 dias e, passado esse período experimental, os cães foram eutanasiados, e se realizou a remoção cirúrgica dos dentes e periápices, a fixaçáo e a desmineralizaçáo. Posteriormente, realizou-se a rotina histológica, digitalização e analise em relação à existência de patologia periapical com auxílio do teste de Kruskal-Wallis. Resultados: Observou-se que, em relação às técnicas, a termoplastificação por ondas contínuas de condensação associada à técnica de injeção mostrou melhores condiçóes periapicais quando comparada à técnica de condensação lateral $(\mathrm{p}=0.0055)$, sendo que a utilização dessa técnica resultou em reaçóes inflamatórias mais intensas para o cimento RealSeal SE $(\mathrm{p}=0.002)$. Em relaçáo aos cimentos avaliados, o RealSeal SE mostrou-se menos eficaz em evitar a percolação, produzindo maiores níveis de inflamação crônica independentemente do sistema de obturação $(\mathrm{p}=0.0088)$. Conclusão: o sistema termoplástico proporcionou melhores respostas inflamatórias e o cimento RealSeal comportou-se igualmente ao cimento AH Plus.
\end{abstract}

Descritores: Obturação do canal radicular • Infiltração dentária • Periodontite periapical.

\section{ABSTRACT}

Introduction: This study aims to evaluate the periapical inflammatory responses resulting from coronary infiltration in dog's teeth obturated using different resin sealers (AH Plus, RealSeal and RealSeal SE) and different obturation techniques (lateral condensation and thermoplastic). Method: For this study, premolars, from five dogs had endodontic treatment and were obturated according to their experimental groups as follows: GI-AHPlus/lateral condensation, GII-AH Plus/thermoplastic, GIII-RealSeal/lateral condensation, GIV-RealSeal/thermoplastic, GV-RealSeal SE/lateral condensation, GVI-RealSeal SE/ thermoplastic, a positive control group and a negative control group. The coronal access was left exposed to the oral environment for a period of 75 days, and after this experimental period, the dogs were euthanized, teeth and periapical tissue were removed, fixed and demineralized. The histological routine was made and each cut was digitalized and compared using the Kruskal-Wallis test. Results: thermoplastification by continuous wave of condensation associated with the injection technique showed better periapical conditions than what was seen for the lateral condensation technique $(p=0.0055)$. On the other hand, for the sealers evaluated, the condensation technique resulted in more intense inflammatory reactions when the sealer RealSeal SE was used ( $\mathrm{p}=0.002)$. In relation to the sealers evaluated, RealSeal SE was seen to be less effective against percolation, thus producing greater levels of chronic inflammation irrespective of the obturation system employed ( $\mathrm{p}=0.0088)$. Warm vertical condensation showed better sealing properties, and AH Plus behave as Real Seal sealer.

DESCRIPTORS: Root canal obturation • Dental leakage • Periapical periodontitis

\footnotetext{
* Doutorando em Endodontia pela Faculdade de Odontologia da Universidade de Sáo Paulo (FOUSP) e Professor assistente da disciplina de Endodontia da Faculdade de Odontologia da Universidade Santa Cecília (FO-UNISANTA).

** Professor Titular da disciplina de Endodontia da Faculdade de Odontologia da Universidade de São Paulo (FOUSP) e Faculdade de Odontologia da Universidade Santa Cecília (FO-UNISANTA) FO-UNISANTA.

*** Professor Doutor do Departamento de Cirurgia da Faculdade de Medicina Veterinária e Zootecnia da Universidade de São Paulo (FMVZ-USP).

**** Mestrando do Departamento de Cirurgia da Faculdade de Medicina Veterinária e Zootecnia da Universidade de Sáo Paulo (FMVZ-USP).

***** Professora Titular da Disciplina de Paotologia Bucal da Faculdade de Odontologia da Universidade de São Paulo (FOUSP).
} 
Akisue E, Gavini G, Gioso MA, Ferreira J, Sousa SCOM. Avaliação da resposta inflamatória periapical em dentes de cães obturados com diferentes cimentos resinosos e técnicas obturadoras. Revista de Odontologia da Universidade Cidade de São Paulo 2009 set-dez; 21(3): 224-32

\section{INTRODUÇÃO}

O sucesso da terapia endodôntica depende das diversas etapas desde a fase de cirurgia de acesso até a restauração do elemento dental, nas quais a fase de obturação do sistema de canais radiculares tem como objetivo o completo selamento do sistema de canais radiculares (Ingle $^{16}$ 1956).

Diversos são os trabalhos que relacionam os insucessos às obturaçốes inadequadas ou incompletas do canal

radicular (Chevigny et al. ${ }^{7}$ 2008, Saunders e Saunders $^{30}$ 1994, Sundqvist et al. ${ }^{37}$ 1998). Essas falhas de selamento tridimensional do conduto radicular favorecem o processo de percolação marginal.

A infiltração apical no canal radicular é descrita como o movimento de fluidos, microrganismos e suas toxinas pelo forame apical e a infiltração coronária como ocorrendo o mesmo pela abertura cervical. Ambos proporcionam percolação pela interface entre o material obturador e a parede de dentina que pode ocasionar a chegada de microrganismos na regiáo periapical ou que, ao recontaminarem o conduto, esses produtos nutrem bactérias remanescentes da etapa de preparo do canal. Tal acontecimento passa a induzir a continuidade ou aparecimento de um processo patológico ( $\mathrm{Nair}^{26} 2006$, Siqueira $^{32}$ 2005, Siqueira e Roças ${ }^{33}$ 2008)

Para a análise da eficácia do selamento marginal, vários são os trabalhos que usam metodologias que empregam marcadores não biológicos (corantes, transporte de fluidos e penetração de glicose) e marcadores biológicos (bactérias e endotoxinas). Porém, a análise da resposta periapical diante do tratamento endodôntico só pode ser avaliada de forma confiável em modelos experimentais in vivo (Wu e Wesselink ${ }^{42}$ 1993)

$\mathrm{Na}$ tentativa de minimizar tais falhas, atualmente tem-se dado maior ênfase às técnicas de obturação termoplastificadas que proporcionam preenchimentos com maior densidade de material sólido (Akisue ${ }^{1}$ 2003; Jacobson et al..$^{18}$ 2002; Siqueira et al. ${ }^{34}$ 2000), e também aos novos cimentos à base de resinas ou metacrilatos que incorporam a ideia da adesão dentinária concebida para a dentística restauradora com o uso de agentes condicionantes compostos de monômeros ("primer").

Diversos trabalhos científicos comprovam a eficiência do sistema de condensação vertical aquecida ou por ondas contínuas de condensação (System $\mathrm{B}^{\circledast}$ ) associada ao sistema de obturação por injeção de gutapercha Obtura II ${ }^{\oplus}$.
Poucos trabalhos in vivo avaliam a eficiência desses novos cimentos endodônticos resinosos à base de metacrilatos com relação à percolação marginal, seja utilizada com técnicas de obturaçâo convencionais ou termoplásticas. Além disso, atualmente, novos cimentos à base de metacrilatos têm incorporado num único produto o agente condicionante (primer) que antes era utilizado previamente à aplicaçáo do cimento.

Portanto, o objetivo deste trabalho é avaliar as respostas inflamatórias resultantes de percolação coronárias em dentes de cães obturados com diferentes cimentos resinosos e diferentes técnicas de obturação.

\section{MATERIAL E MÉTODOS}

Para este estudo foram utilizados cinco cães de raça não definida (SRD), de idade entre 5 e 8 anos e de peso entre 15 a 25 quilos, adquiridos no canil do Departamento de Cirurgia (VCI) da Faculdade de Medicina Veterinária e Zootecnia da Universidade de São Paulo (FMVZ-USP).

Os dentes obturados foram os pré-molares inferiores e superiores. O protocolo de pesquisa foi aprovado pelos Comitês de Ética em Pesquisa - Subcomissão de Bioética de Animais da FOUSP e Comissão de Bioética da FMVZ-USP .

Em todos os procedimentos cirúrgicos os cães foram submetidos à anestesia geral conforme o protocolo recomendado pelo Laboratório de Odontologia Comparada do Departamento de Cirurgia da FMVZ - USP. Esse protocolo consiste de pré-anestesia com Acepromazina (Acepran $^{\oplus} 0.2 \%$ ), indução com Propofol (Provive ${ }^{\circledast} 1 \%$ ) e manutenção da anestesia com Isoflurano (Isothane ${ }^{\circ}$ ) pelo tempo necessário.

Inicialmente foi realizada a radiografia periapical dos dentes a serem submetidos ao tratamento endodôntico, raspagem para remoção da placa bacteriana e do tártaro, e assepsia dos tecidos moles e dentes com soluçáo de clorexidina a $2 \%$.

A etapa do tratamento endodôntico propriamente dita constituiu-se da cirurgia de acesso, preparos da entrada dos canais realizados com auxilio da instrumentação rotatória utilizando-se instrumentos rotatórios K3 ISO 25/.12 e Pré-Race ISO 35/.08 e 40/.10, determinação do comprimento de trabalho por meio radiográfico a uma distância entre $1 \mathrm{~mm}$ e $1.5 \mathrm{~mm}$ aquém do vértice radiográfico da raiz e preprao do canal propriamente dito com instrumentos K3 seguindo a sequência Procedure 
Akisue E, Gavini G, Gioso MA, Ferreira J, Sousa SCOM. Avaliação da resposta inflamatória periapical em dentes de cães obturados com diferentes cimentos resinosos e técnicas obturadoras. Revista de Odontologia da Universidade Cidade de São Paulo 2009 set-dez; 21(3): 224-32

Pack (25/.10, 25/.08, 40/.06, 35/.06, 30/.06, 25/.06) até a feitura do preparo apical com um instrumento 40/.06, sempre utilizando-se o creme de Endo PTC associado a uma irrigação de $5 \mathrm{~mL}$ de hipoclorito de sódio a cada troca de instrumento.

Concluído o preparo químico-cirúrgico, os canais radiculares foram irrigados com $6 \mathrm{~mL}$ da solução de ácido cítrico a $15 \%$, seguida de $6 \mathrm{~mL}$ da solução de clorexidina a $2 \%$ e secos por aspiração com pontas capilares finas e com cones de papel absorvente.

Os dentes assim preparados foram distribuídos aleatoriamente em 8 grupos de acordo com as técnicas de obturação, a saber: Grupo I (AHCL) - 12 canais obturados com o cimento AHPlus e técnica de condensação lateral; Grupo II (AHCW) - 12 canais obturados com o cimento AHPlus e técnica termoplástica por ondas contínuas de condensação (CWC)/injeção; Grupo III (RSCL) - 12 canais obturados com o cimento RealSeal e técnica de condensação lateral; Grupo IV (RSCW) - 12 canais obturados com o cimento RealSeal e técnica termoplástica por ondas contínuas de condensação (CWC)/injeção; Grupo V (SECL) - 12 canais obturados com o cimento RealSeal SE e técnica de condensação lateral; Grupo VI (SECW) - 12 canais obturados com o cimento RealSeal SE e técnica termoplástica por ondas contínuas de condensação (CWC)/injeção; Controle positivo - 10 canais sem material obturador e Controle negativo - 10 canais obturados com cimento AH Plus e técnica de condensação lateral, sendo posteriormente restaurados com resina composta.

Para a técnica termoplástica Elements Obturation Unit que associa as técnicas de ondas continuas de condensação (CWC) e injeção de material sólido plastificado, foi escolhido o condensador LM .08 ou M .10 que apresentava justeza ao canal radicular quando a sua extremidade localizava-se entre 3 e $4 \mathrm{~mm}$ aquém do preparo apical. Com o aparelho System B do Elements Obturation Unit (SybronEndo Corp., Orange, CA, USA) calibrado na temperatura de $200^{\circ} \mathrm{C}$ para a guta-percha e $150^{\circ} \mathrm{C}$ para o Resilon, o condensador foi introduzido no canal radicular previamente preenchido com o cimento e o material sólido até que este alcançasse o limite anteriormente estabelecido. Ao atingir esse limite, cessou-se o aquecimento, permanecendo o condensador sob pressão durante 10 segundos. Após esse período, acionou-se rapidamente o aquecimento e foi removido o condensador do interior do canal. Realizou-se a condensação do material termoplastificado no terço apical com auxílio de condensadores. Completou-se o preenchimento dos terços médio e cervical com sucessivas etapas de injeção de guta-percha ou Resilon termoplastificados pelo sistema Extruder do Elements Obturation Unit (SybronEndo Corp., Orange, CA, USA) e condensação vertical a frio com os condensadores manuais.

À sua vez, para a técnica de condensação lateral foram utilizados cones de guta-percha FM de guta-percha ou Resilon cujas pontas foram calibradas no diâmetro correspondente ao preparo apical com o auxilio de régua calibradora. $\mathrm{O}$ cone principal foi introduzido no conduto conjuntamente ao cimento obturador e a técnica de condensação lateral realizada com auxílio de espaçadores digitais ou com espaçadores de conicidade 0.04 quando possível. Esses espaçadores promoviam espaços na obturação que foram preenchidos com cones de guta-percha $\mathrm{RS}$ ou cones de Resilon F até o completo preenchimento do canal radicular.

Os canais obturados pelo sistema RealSeal/Resilon foram fotopolimerizadas por 40 segundos logo após o término da condensação. Ao final dos procedimentos de obturação, todos os dentes foram selados com cimento temporário pelo período de 7 dias.

Após a sessão de instrumentação e obturação foi administrado cloridrato de tramadol e ketoprofeno visando respectivamente ação analgésica e ação antiinflamatória no pós-operatório imediato.

Após o período de 1 semana, os cães foram anestesiados novamente para a remoção do selamento coronário.

As cavidades coronárias ficaram entâo expostas ao meio bucal por um período de 75 dias.

Passado o período experimental, os cães foram ortotanásiados por superdosagem de anestésico, iniciada com pré-anestesia com Acepromazina, indução com Propofol e superdosagem propriamente dita com Thiopental na

dosagem de $50 \mathrm{mg} / \mathrm{kg}$. Na sequência foi realizada a injeção de $10 \mathrm{~mL}$ de cloreto de potássio para indução da parada cardíaca.

Uma vez constatada a morte, realizava-se a perfusão de formol a $10 \%$ através da carótida e a remoção das partes correspondentes aos pré-molares e incisivos da maxila. Logo após a remoção, as peças foram colocadas em solução de formol a $10 \%$ e fixadas por $72 \mathrm{hs}$.

Depois de fixadas foram lavadas e desmineralizadas em solução de ácido fórmico a $20 \%$ + citrato de sódio a $10 \%$ pelo período mínimo de 90 dias. Para acelerar 
Akisue E, Gavini G, Gioso MA, Ferreira J, Sousa SCOM. Avaliação da resposta inflamatória periapical em dentes de cães obturados com diferentes cimentos resinosos e técnicas obturadoras. Revista de Odontologia da Universidade Cidade de São Paulo 2009 set-dez; 21(3): 224-32

o processo de desmineralização, após as duas primeiras semanas, as peças foram fragmentadas em pequenos blocos contendo uma ou duas raízes, e mensalmente foi verificada a possibilidade do corte de excessos do material (dente e osso).

Constatada a desmineralização por meio de tomadas radiográficas e análise da consistência do material, as peças foram submetidas à rotina histológica, sendo lavadas, desidratadas, diafanizadas em xilol e incluídas em parafina.

Realizou-se a microtomia em cortes seriados com espessura de $6 \mu \mathrm{m}$, sendo dois cortes para cada região apical das raízes. Para a análise histopatológica, os cortes foram corados com hematoxilina e eosina (HE).

Cada corte histológico foi digitalizado e analisado em relação à existência de patologia periapical por três avaliadores (patologistas) independentes. A existência de inflamação periapical foi pontuada por meio de escores segundo os seguintes aspectos:

Reação inflamatória aguda (PMN) ou reação inflamatória crônica (Infiltrado mononuclear) divididas nos escores: Escore 0 = Ausente $/$ Discreta; Escore 1 = Moderada; Escore 2 = Intensa / Severa.

Os dados obtidos foram tabulados e posteriormente submetidos à análise estatística.

\section{RESULTADOS}

No quadro 2 encontram-se dispostas as frequências dos fenômenos histopatológicos avaliados em forma de escores, distribuídas em função de suas ocorrências em cada grupo experimental.

Quando comparadas às técnicas, a técnica termoplástica por ondas contínuas de condensação associada à técnica de injeção $(\mathrm{CW})$ mostrou melhores condiçôes periapicais quando comparada à técnica de condensação lateral (CL), sendo essa diferença estatisticamente significante $(\mathrm{p}=0.0055)$.

Analisando somente a técnica da condensação lateral variando os cimentos, não se encontrou diferença es- tatisticamente significante entre os cimentos $\mathrm{AH}$ Plus, RealSeal e RealSeal SE ( $\mathrm{p}=0.7551)$. Do mesmo modo, ao se analisar a técnica de ondas contínuas de condensaçâo associada à técnica por injeção, variando somente os cimentos novamente, observou-se diferença significante $(\mathrm{p}=0.002)$ entre os cimentos.

Quando comparados os cimentos endodônticos utilizados (AH Plus, RealSeal e RealSeal SE), independente da técnica de obturação utilizada, observou-se diferença significante $(\mathrm{p}=0.0088)$.

Ao analisar somente o cimento AH Plus (AH) e o cimento RealSeal (RS) variando as técnicas de obturação, encontrou-se diferença estatisticamente significante entre as técnicas ( $\mathrm{p}=0.0082$ e $\mathrm{p}=0.190$ respectivamente), quando a técnica CWC mostrou respostas inflamatórias menos intensas.

Quando analisado o cimento RealSeal SE (SE) variando-se a técnica de obturação, esta não apresentou diferença estatisticamente significante entre a técnica convencional - CL - e a termoplástica - CWC $(\mathrm{p}=0.9954)$.

O grupo-controle positivo, quando comparado aos demais grupos experimentais, apresentou diferença estatisticamente significante $(\mathrm{p}<0.0001)$. Já o grupo-controle negativo não mostrou diferença estatística quando comparados aos grupos GI, GII, GIII, GVI e GV; exceto quando comparado ao GVI $(\mathrm{p}<0.0001)$.

\section{DISCUSSÃO}

Ao comparar os dois sistemas (condensação lateral e termoplástificaçáo) in vivo, os resultados mostraram melhores respostas inflamatórias resultantes da percolação nos dentes obturados com auxílio da técnica termoplástica $(\mathrm{p}=0.0055)$, onde ocorreu ausência ou inflamação leve em $81.4 \%$ e severa em $4.6 \%$ dos casos. Contrariamente, para o grupo obturado pela técnica de condensação lateral, observou-se ausência/inflamação leve em $62 \%$ e severo em $16.6 \%$ das análises.

Quadro 2 - Frequência dos fenômenos histopatológicos em cada grupo experimental.

\begin{tabular}{ccccccccc}
\hline Aspectos Histopatológicos & AHCL & AHCWW & RSCL & RSCW & SECL & SECW & CP & CN \\
\hline Ausência de infiltrado inflamatório & 17 & 30 & 18 & 29 & 17 & 11 & 1 & 24 \\
Infiltrado inflamatório crônico leve & 9 & 2 & 2 & 1 & 4 & 15 & 5 & 6 \\
Infiltrado inflamatório crônico moderado & 6 & 4 & 11 & 5 & 6 & 6 & 10 & 0 \\
Infiltrado inflamatório crônico severo & 4 & 0 & 5 & 1 & 9 & 4 & 14 & 0 \\
\hline \hline
\end{tabular}


Akisue E, Gavini G, Gioso MA, Ferreira J, Sousa SCOM. Avaliação da resposta inflamatória periapical em dentes de cães obturados com diferentes cimentos resinosos e técnicas obturadoras. Revista de Odontologia da Universidade Cidade de São Paulo 2009 set-dez; 21 (3): 224-32

Esses resultados são semelhantes aos alcançados por Shipper et al. ${ }^{31}$ (2005) que avaliaram in vivo a condição da região periapical de dentes obturados com guta-percha associada ao cimento AH Plus ou com o Resilon associado ao cimento Epiphany (Sistema Monobloco Resilon - RMS) observando inflamaçóes de nível médio em $82 \%$ dos casos obturados com a associação guta-percha/ AH Plus e em 19\% dos casos obturados com o sistema RMS ( $\mathrm{p}<0.05$ ); concluindo que a ocorrência de menores índices de inflamação periapical era devida à capacidadede selamento marginal.

Essa melhor capacidade de selamento se deve à propriedade do sistema termoplástico por ondas contínuas de condensação em promover um melhor preenchimento do canal principal e dos canais laterais com o material obturador (De Deus et al. ${ }^{9}$ 2008, Epley et al..$^{12} 2006$, Goldberg et al..$^{14}$ 2001, Jarret et al. ${ }^{20} 2004$, Lea et al..$^{23}$ 2005) devido ao chamado "efeito cunha" conseguido por esse tipo de procedimento.

Tal efeito pode ser descrito como uma maior força e pressão sobre o material obturador, o que permite a eficiente adaptação desse junto à parede dentinária e uma maior penetraçáo do material nos túbulos dentinários.

Blum et al. ${ }^{4}$ (2001), utilizando um novo aparelho - Endógrafo - que permite analisar as mesmas forças e também a força de cunha obtida durante procedimentos de obturação com a técnica System B, mostraram ser essa técnica a melhor em relação à capacidade de resultar em adequadas verticais $(16 \pm 2 \mathrm{~N})$, horizontais $(5 \pm 1 \mathrm{~N})$ e efeito de cunha $(9 \pm 1 \mathrm{~N})$ na guta-percha, as quais podem levar a um melhor preenchimento do canal e consequentemente um melhor selamento apical.

Sabe-se também que o limite de aquecimento com o System B possui influência no aquecimento do material obturador e consequentemente na melhora da adaptaçáo da guta-percha junto à parede dentinária do terço apical (Jung et al. ${ }^{21}$ 2003).

Jung et al. ${ }^{21}$ (2003), ao analisarem a área preenchida pelo sistema System B, variando-se a temperatura e a profundidade da introduçâo da ponta aquecedora aquém do comprimento de trabalho (CRT), obturaram blocos com canais simulados de acordo com os seguintes grupos: $\mathrm{G} 1-100^{\circ} \mathrm{C}$ a $4 \mathrm{~mm}, \mathrm{G} 2-200^{\circ} \mathrm{C}$ a $4 \mathrm{~mm}$, G3- $350^{\circ} \mathrm{C}$ a $4 \mathrm{~mm}, \mathrm{GIV}-200^{\circ} \mathrm{C}$ a $2 \mathrm{~mm}$ e GV- $200^{\circ} \mathrm{C}$ a $4 \mathrm{~mm}$ acrescido de condensação a frio a $3 \mathrm{~mm}$. Os resultados mostraram haver diferença entre as temperaturas $(\mathrm{p}>0.05)$ e que, ao nível de $1 \mathrm{~mm}$ aquém do CRT, a profundidade de introdução da ponta interfere na porcentagem de área preenchida pelo material obturador, onde encontraram maiores índices em $200^{\circ} \mathrm{C}$ a $2 \mathrm{~mm}$ em relação a $4 \mathrm{~mm}$.

Os mesmos bons resultados foram encontrados na análise dos cimentos separadamente, onde ocorreu somente a variação da técnica de obturação, tendo a técnica termoplástica (CWC) melhores resultados em relação à resposta tecidual resultante da percolação tanto para o cimento AH Plus ( $\mathrm{p}=0.0082)$ quanto para o RealSeal $(\mathrm{p}=0.0190)$ quando comparada à técnica de condensação lateral (CL).

Em contrapartida, na mesma análise para o RealSeal SE, não foi encontrada diferença estatisticamente significante entre as duas técnicas obturadoras $(\mathrm{p}=0.9954)$, podendo isso ser explicado por possíveis falhas da adesão desse cimento "self-etched" que será mais minuciosamente explicados quando da discussão sobre os cimentos.

Nos últimos anos, diversos trabalhos in vitro têm sido realizados a fim de se avaliarem as propriedades físicas e químicas desses cimentos à base de metacrilatos. Como esse novo sistema de obturação baseia-se nos princípios adesivos oriundos da dentística restauradora, é sábido que a durabilidade de restauraçóes adesivas se degradam após um período mínimo de 3 meses (De Munck ${ }^{10}$ 2005), e isso permite a mesma premissa ser aplicada aos novos sistemas de obturação que contêm polímeros e monômeros em sua composição (Souza ${ }^{36}$ 2007).

Uma característica que torna essa degradação possível é a alta susceptibilidade desses materiais, incluindo-se os cimentos resinosos à base de metacrilatos; é a sorção de água (Ito et al. ${ }^{17}$ 2005, Malacarne et al. ${ }^{25}$ 2006) que resulta na plastificação dos polímeros por hidrólise com consequente diminuição das propriedades físico-químicas e longevidade da interface adesiva (Kalachandra e Turner ${ }^{22}$ 1987).

Donnelly et al. ${ }^{11}$ (2007) mostraram que o Epiphany possui uma sorção de água cerca de 8 vezes maior que o AH Plus (8,02\%, contra 1,07\%), podendo isso ser a justificativa para os seus maiores índices de solubilidade (Donnelly et al. ${ }^{11}$ 2007; Versiani et al..$^{41}$ 2006) quando comparado ao $\mathrm{AH}$ Plus e um inadequado comportamento a longo prazo (Paque e Sirtes ${ }^{27}$ 2007).

Outra característica observada é a alta contração de polimerização dos monômeros resinosos (Carvalho et al. ${ }^{6}$ 1996) e, seguindo esse princípio, Hammad et al. ${ }^{15}$ 
Akisue E, Gavini G, Gioso MA, Ferreira J, Sousa SCOM. Avaliação da resposta inflamatória periapical em dentes de cães obturados com diferentes cimentos resinosos e técnicas obturadoras. Revista de Odontologia da Universidade Cidade de São Paulo 2009 set-dez; 21(3): 224-32

(2008) mostraram o mesmo acontecendo em cimentos resinosos que possuíam UDMA na sua composição.

Apesar de cimentos duais terem um grau de conversão (polimerização) extremamante dependente da fotoativação, atuais cimentos de cura dual permitem uma lenta polimerização química nas áreas onde não ocorreu a fotoativação, o que possibilita a sua conversão em polímero estável (Braga ${ }^{5}$ 2002). Porém Souza ${ }^{36}$ (2007) mostrou que o grau de conversáo na regiáo apical de dentes obturados com o cimento Epiphany corresponde a 30\% da taxa de conversão obtida no terço cervical que recebeu a fotoativação. Esses resultados têm efeito negativo sobre as propriedades mecânicas e a estabilidade química desse cimento e, consequentemente, na capacidade de vedamento. Achados semelhantes foram mostrados por Beriat et al. ${ }^{3}$ (2009), onde o cimento Epiphany apresentou incompleta polimerização após duas semanas.

$\mathrm{Na}$ endodontia, a capacidade de selamento é influenciada principalmente pela adesividade dos cimentos endodônticos que, por sua vez, podem ser mensuradas pela resistência de uniáo cimento/dentina (Tagger et al. ${ }^{38}$ 2003). Teoricamente, a resistência de união à dentina de um sistema adesivo baseia-se na somatória de diversos fatores, porém, dentre muitos, pode-se citar o mais importante: a adesão conseguida pela hibridização e formação de prolongamentos resinosos chamados "tags" (Pashley et al. ${ }^{28} 1995$ ).

O mesmo trabalho de $\operatorname{Souza}^{36}$ (2007) analisou a formação de camada híbrida e tags pelos cimentos AH Plus e Epiphany; e mostrou que o condicionador primer de acidez forte $(\mathrm{pH} 0.3)$ do cimento à base de metacrilato, quando utilizado conjuntamente com prévio condicionamento, é capaz de promover uma desmineralização dentinária e exposição de fibras colágenas numa profundidade de $7.95 \mu \mathrm{m}$ e consequente formaçáo de camada híbrida numa espessura de $0.82 \pm 0.23 \mu \mathrm{m}$. Em relaçáo aos tags, a mesma autora mostrou que a alta fluidez e natureza hidrofílica do cimento Epiphany podem resultar em alta densidade de longos tags na fotomicrografias de varredura, diferentemente do AH Plus que possui característica hidrofóbica e menor escoamento.

Um dos métodos mais confiáveis para análise da resistência de união é o ensaio de push-out (Fisher et al. ${ }^{13}$ 2007, Jainaen et al. ${ }^{19}$ 2007). Trabalhos avaliando a adesão dos cimentos que contêm metacrilato mostram baixos índices de resistência (Rahimi et al. ${ }^{29}$ 2009, Sly ${ }^{35} 2007$, Ureyen Kaya et al..$^{40}$ 2008). Porém, o fato de avaliarem duas interfaces (dentina/cimento e cimento/cone) gera dúvidas quanta à validade metodológica. Em rumo, Tay et al. ${ }^{39}$ (2007) citam a não adesão do cone de Resilon ao cimento Epiphany.

Assim, Souza ${ }^{36}$ (2007) avaliou a adesão somente do cimento Epiphany à dentina radicular pelo método push out e mostrou também menores valores de adesão que foram $6.3 \pm 5.3 \mathrm{MPa}$ para o Epiphany contra $17.8 \pm 7.5 \mathrm{MPa}$ para o AH Plus . A justificativa para esse pior resultado provavelmente deve-se ao pequeno grau de conversão alcançado pela polimerização unicamente química. Estudo semelhante realizado por Akisue et al.2, (2005), ao polimerizarem os corpos de prova previamente ao ensaio de push out, mostrou uma melhor adesáo do cimento RealSeal $(4,338 \pm 0,625 \mathrm{MPa})$ em relação ao AH Plus $(2,688 \pm 0,301 \mathrm{MPa})$, podendo isso contribuir para a assertiva de que a adesão também sofre influência do grau de conversão.

Embora os cimentos à base de metacrilato tenham desvantagens em relação às propriedades físico-químicas (Tay e Pashley ${ }^{39}$ 2007), aparentemente mostram adequado comportamento em avaliaçóes in vivo e bons resultados clínicos (Cotton et al. ${ }^{8}$ 2008).

Trabalhos in vivo de Shipper et al. ${ }^{31}$ (2005) e Leonardo et al..$^{24}$ (2007) mostram melhor eficiência do cimento à base de metacrilato Epiphany ou RealSeal no selamento marginal. Porém, neste estudo, quando comparado ao $\mathrm{AH}$ Plus, não houve diferença entre ambos ao se analisarem somente os cimentos, independentemente da técnica obturadora ( $>0.05)$, quando da utilização apenas da técnica de condensação lateral, variando-se os cimentos ( $\mathrm{p}=0.7551)$, e quando do uso da termoplastificação com variação do cimento $(\mathrm{p}>0.05)$.

Essas igualdades podem sugerir que o tempo experimental decorrido (75 dias) possibilita uma maior solubilidade e consequente percolação, ao contrário dos testes laboratoriais onde, na maioria das vezes, os cimentos são analisados logo após a sua polimerização.

Tentando melhorar as propriedades físico-quimicas do cimentos Epiphany ou RealSeal, uma segunda geração foi introduzida no mercado recentemente com o nome de Epipnahy SE ou RealSeal SE. Nesta, os componentes condicionantes do primer estáo incorporados ao cimento, o que elimina uma etapa de condicionamento. Provavelmente, a incorporação do primer ao cimento justifica-se pelos inconvenientes causados pela alta acidez do condicionador, já que ácidos interferem na reação 
Akisue E, Gavini G, Gioso MA, Ferreira J, Sousa SCOM. Avaliação da resposta inflamatória periapical em dentes de cães obturados com diferentes cimentos resinosos e técnicas obturadoras. Revista de Odontologia da Universidade Cidade de São Paulo 2009 set-dez; 21(3): 224-32

química peróxido-amina e, consequentemente, diminuem o grau e conversão.

\section{CONCLUSÃO}

Por ser um produto recente, não foram encontrados trabalhos em relação à capacidade de selamento deste cimento.

Os resultados obtidos neste estudo mostram a ineficiência desse cimento auto-condicionante (self-etched) em evitar a percolação, pois, ao analisar a técnica termoplástica variando-se o tipo de cimento endodôntico, os resultados mostram uma diferença $(\mathrm{p}=0.002)$ entre o cimento RealSeal SE e os demais testados. Não houve diferença quanto ao uso da técnica convencional da condensação lateral $(\mathrm{p}=0.07551)$.

Quando analisados somente os cimentos, independentemente da técnica, o ReaSeal SE mostrou diferença significante $(\mathrm{p}=0.0088)$ quando comparado ao AH Plus, porém, não mostrou diferença em relação ao RealSeal $(\mathrm{p}>0.05)$.

Novamente, voltando aos princípios adesivos, uma das possíveis justificativas é a falta de hibridização dentinária, já que a existência de áreas de dentina desmineralizada e náo infiltrada abaixo da camada híbrida contraria o conceito de que os adesivos self-etched desmineralizam e infiltram-se na dentina na mesma extensão. Existe, ainda, a possibilidade da ocorrência de menor grau de conversão característica dos cimentos duais self-etched e de menor penetração do material nos túbulos dentinários formando tags.

Embora este estudo tenha demonstrado bons resultados no uso de cimentos à base de metacrilato, principalmente quando associados às técnicas termoplásticas, o mesmo parece náo ter alcançando o idealismo do conceito de monobloco. A utilização de cimentos com propriedades adesivas parece ter um futuro promissor, porém, mais estudos laboratoriais e clínicos deverão ser realizados a fim de se comprovar sua verdadeira efetividade. Muitas mudanças devem e deverão acontecer na composição desses materiais, para que se possa atingir a sonhada absoluta impermeabilização do sistema de canais radiculares. 
Akisue E, Gavini G, Gioso MA, Ferreira J, Sousa SCOM. Avaliação da resposta inflamatória periapical em dentes de cães obturados com diferentes cimentos resinosos e técnicas obturadoras. Revista de Odontologia da Universidade Cidade de São Paulo 2009 set-dez; 21(3):

\section{REFERÊNCIAS}

1. Akisue E. Análise in vitro da percolação apical em dentes obturados empregando-se o método de infiltração e quantificação do nível de endotoxina [Mestrado]. São Paulo: Faculdade de Odontologia da USP; 2003.

2. Akisue E, Gavini G, Teixeira FB. Análise da adesão de cimentos endodônticos resinosos à superfície dentinária radicular [resumo Pc061]. Braz Oral Res;19:210.

3. Beriat NC, Ertan A, Cehreli ZC, Gulsahi K. Timedependent conversion of a methacrylate-based sealer polymerized with different light-curing units. J Endod 2009;35(1):110-2.

4. Blum JY, Cathala C, Machtou P, Micallef JP. Analysis of the Endogrammes developed during obturations on extracted teeth using System B. J Endod 2001;27(11):661-5.

5. Braga RR, Cesar PF, Gonzaga CC. Mechanical properties of resin cements with dofferent activation modes. J Oral Rehabil 2002;29:257-62.

6. Carvalho RM, Pereira JC, Yoshiyama M, Pashley DH. A review of polymerization contraction: The influence of stress development versus stress relief. Oper Dent 1996;21(1):17-24.

7. Chevigny C, Dao TT, Basrani BR, Marquis V, Farzaneh M, Abitbol S, et al. Treatment Outcome in Endodontics: The Toronto Study_-Phase 4: Initial Treatment. Int Endod J 2008;34(3):258-63.

8. Cotton TP, Schindler WG, Schwartz SA, Watson WR, Hargreaves KM. A retrospective study comparing clinical outcomes after obturation with Resilon/ Epiphany or gutta-percha/Kerr sealer. J Endod 2008;34(7):789-97.

9. De Deus G, Reis C, Beznos D, DDS, Abranches AMG, Coutinho-Filho T, Paciornik S. Limited ability of three commonly used thermoplasticized gutta-percha techniques in filling oval-shaped canals. $J$ Endod 2008;34(11):1401-5.

10. De Munck J, Van Landuyt K, Peumans M, Poitevin A, Lambreschts P, Braem M, et al. A critical review of the durability of adhesion to tooth tissue: Methods and Results. J Dent Res 2005;84(2):118-32.
11. Donnelly A, Sword J, Nishitani Y, Yoshiyama M, Agee K, Tay FR, et al. Water sorption and solubility of methacrylate resin-based root canal sealers. $J$ Endod 2007; 33(8):990-4.

12. Epley SR, Fleischman J, Hartwell G, Cicalese C. Completeness of root canal obturations: Epiphany techniques versus Gutta-Percha techniques. J Endod 2006;32(6):541-4.

13. Fisher MA, Berzins DW, Bahcall JK. An in vitro comparison of bond strength of various obturation materials to root canal dentin using a push out test design. J Endod 2007;33(7):856-8.

14. Goldberg F, Artaza L, De Silvio A. Effectiveness of different obturation techniques in the filling of simulated lateral canals. J Endod 2001;27(5):362-4.

15. Hammad M, Qualtrough A, Silikas N. Extended setting shrinkage behavior of endodontic sealers. $J$ Endod 2008;34(1):90-3.

16. Ingle JI. Root canal obturation. JADA 1956; 53(1): 47- 55

17. Ito S, Hashimoto M, Wadgonkar B, Svizero N, Carvalho $\mathrm{RM}$, Yiu $\mathrm{C}$ et al. Effect of resin hidrophilicity on water sorption and changes in modulus of elasticity. Biomaterials 2005;26:6449-59.

18. Jacobson Hl, Xia T, Baumgartner JC, Marshall JG, Beeler WJ. Microbial leakage evaluation of the continuous wave of condensation. $J$ Endod 2002;28(4):269-71.

19. Jainaen A, Palamara JEA, Messer HH. Pus-out bond strengths of the dentine-sealer interface with and without a main core. Int Endod J 2007;40:882-90.

20. Jarret IS, Marx D, Covey D, Karmazin, Lavin M, Gound T. Percentage of canals filled in apical cross sections - an in vitro study of seven obturation techniques. Int Endod J 2004;37(6):392-8.

21. Jung IY, Lee SB, Kim ES, Lee CY, Lee SJ. Effect of different temperatures and penetration depths of a System B plugger in the filling of artificially created oval canals. Oral Surg Oral Med Oral Pathol Oral Radiol Endod 2003;96(4):453-7. 
Akisue E, Gavini G, Gioso MA, Ferreira J, Sousa SCOM. Avaliação da resposta inflamatória periapical em dentes de cães obturados com diferentes cimentos resinosos e técnicas obturadoras. Revista de Odontologia da Universidade Cidade de São Paulo 2009 set-dez; 21(3): 224-32

22. Kalachandra S, Turner DT. Water sorption of polymethacrylate networks: bis-GMA/TEGDMA copolymers. J Biomed Mater Res 1987;21:329-38.

23. Lea CS, Apicella MJ, Mines P, Yancich PP, DDS, Parker MH. Comparison of the obturation density of cold lateral compaction versus warm vertical compaction using the continuous wave of condensation technique. J Endod 2005;31(1):37-9.

24. Leonardo MR, Barnett F, Debelian GJ, de Pontes Lima RK, Bezerra da Silva LA. Root canal adhesive fillling in dog's teeth with or without coronal restoration: A histopathological evaluation. J Endod 2007;33(11):1299-303.

25. Malacarne J, Carvalho RM, de Goes MF, Svizerd V, Tay FR, Pashley DH. Water sorption/solubility of dentinal adhesives resins. Dent Mater 2006; 22: 973 80.

26. Nair PNR. On the causes of persistent apical periodontitis: a review. Int Endod J 2006;39(4):249-81.

27. Paqué F, Sirtes G. Apical sealing ability of Resilon/ Epiphany versus gutta-percha/AH Plus: immediate and 16-months leakage. Int Endod J 2007; 40(9): 722-9.

28. Pashley DH, Ciucchi B, Sano H, Carvalho RM, Russel $\mathrm{CM}$. Bond strength versus dentine structure: a modelling approach. Arch Oral Biol 1995;40(12):110918.

29. Rahimi M, Jainaen A, Parashos P, Messer HH. Bonding of resin-based sealers to root dentin. $J$ Endod 2009; 35(1): 121-4.

30. Saunders WP, Saunders EM. Coronal leakage as a cause of failure in root canal therapy: a review. End Dent Traum 1994;10(3):105-8.

31. Shipper G, Teixeira FB, Arnold RR, Trope M. Periapical inflammation after coronal microbial inoculation of dog roots filled with gutta-percha or Resilon. J Endod 2005;31(2):91-6.

32. Siqueira JF Jr. Reaction of periradicular tissues to root canal treatment: benefits and drawbacks. Endod Topics 2005;10:123-147
33. Siqueira JF Jr, Roças IN. Clinical implications and microbiology of bacterial per sistence after treatment procedures. J Endod 2008;34(11):1291-301.

34. Siqueira JF Jr, Roças IN, Favieri A, Abad EC, Castro AJ, Gahyva SM. Bacterial leakage in coronally unsealed root canals obturated with 3 different techniques. Oral Surg Oral Med Oral Pathol Oral Radiol Endod 2000;90(5):647-50.

35. Sly MM, Moore BK, Platt JA, Brown CE. Push-out bond strength of a new endodontic obturation system (Resilon/Epiphany). J Endod 2007;33(2):160-2.

36. Souza SFC. Cimentos resinosos endodônticos: selamento apical, aspectos micromorfológicos, características físicas e resistência de união à dentina [Doutorado]. São Paulo: Faculdade de Odontologia da USP; 2007.

37. Sundqvist G, Fidgor D, Persson S, Sjorgen U. Microbiologic analysis of teeth with failed endodontic treatment and the outcome of conservative retreatment. Oral Surg Oral Med Oral Pathol Oral Radiol Endod 1998;85(1):86-93.

38. Tagger M, Tagger E, Tjan AHL, Bakland LK. Shearing bond strength of endodontic sealers to guttapercha. J Endod 2003;29(3):191-3.

39. Tay FR, Pashley DH. Monoblocks in root canals: a hypothetical or a tangible goal. $J$ Endod 2007;33(4):391-98.

40. Ureyen Kaya B, Keçeci AD, Orhan H, Belli S. Micropush-out bond strengths of gutta-percha versus thermoplastic synthetic polymer-based systems - an ex vivo study. Int Endod J 2008;41(3):211-18.

41. Versiani MA, Carvalho-Júnior JR, Padilha MIAF, Lacey S, Pascon EA, Sousa-Neto MD. A comparative study of physicochemical properties of $\mathrm{AH}$ Plus and Epiphany root canal sealants. Int Endod J 2006;39:464-71.

42. Wu MK, Wesselink PR. Endodontic leakage studies reconsidered.Part I. Metodology, application and relevance. Int Endod J 1993;26(1):37-43.

Recebido em: 9/2/2009 Aceito em: 1/10/2009 